\title{
Assessment of hand function in women with lymphadenopathy after radical mastectomy
}

\author{
Subham Mistry $^{1}$, Taimul Ali ${ }^{2}$, Mohammed Qasheesh ${ }^{3}$, Rashid Ali Beg ${ }^{3}$, Mohammad Abu Shaphe ${ }^{\text {Corresp., } 3}$, Fuzail \\ Ahmad ${ }^{4}$, Faizan Z Kashoo ${ }^{4}$, Amr S Shalaby ${ }^{5}$ \\ 1 Department of Physiotherapy, KPC Medical College, Kolkata, West Bengal, India \\ 2 Department of Physiotherapy, Peerless Hospitex Hospital \& Research Center, Kolkata, West Bengal, India \\ 3 Department of Physical Therapy College of Applied Medical Sciences, Jazan University, Jazan, Saudi Arabia \\ 4 Department of Physical Therapy \& Health Rehabilitation, College of Applied Medical Science, Majmaah University, Majmaah, Saudi Arabia \\ 5 Faculty of Physical Therapy Basic Science, Cairo University, Cairo, Egypt \\ Corresponding Author: Mohammad Abu Shaphe \\ Email address: mshaphe@jazanu.edu.sa
}

Background. Breast cancer related upper limb lymphedema (BCRL) is a common complication in post-mastectomy patients. It is known to cause upper limb disability, which subsequently may affect the grip strength and hand function. There is little evidence on the objective assessment of functional activities particularly hand function in women with BCRL. Therefore, this study objectively assesses the handgrip strength and hand functions in women with BCRL. Method. A cross-sectional study design was conducted on a sample of women with ( $n=31)$ and without $(n=31)$ BCRL. The Handgrip strength and hand functions were measured using a dynamometer and Jebsen-Taylor hand function test, respectively. Results. The results showed a significantly reduced handgrip strength in women with BCRL as compared to age-matched healthy adult women for both right and left hands $(p<0.05)$. Similarly, hand functions were significantly impaired in women with $B C R L$ as compared to healthy adult women $(p<0.05)$. Reduction in handgrip strength and hand function in women with BCRL were clinically meaningful as indicated by moderate to large effect sizes (Cohen's $d=0.61$ to 0.99 and 0.54 to 3.02, respectively) in all outcomes except power handgrip strength in left hand (Cohen's $d=0.38$ ). Conclusion. The results of this study indicate a significant reduction of hand grip strength and hand function in women with BCRL. Our findings suggest that objective measures of grip strength and function be included in the assessment of women with BCRL to better guide clinical decision making and patient care, which may include management of impairment associated with hand strength and function. Future studies that evaluate hand grip strength and function in a larger sample which includes a more diverse age group of women with BCRL are warranted to confirm the current findings. 


\section{Assessment of Hand Function in Women with 2 lymphadenopathy after radical mastectomy}

3

4 5 6

Subham Mistry ${ }^{1}$, Taimul Ali ${ }^{2}$, Mohammed Qasheesh ${ }^{3}$, Rashid Ali Beg ${ }^{3}$, Mohammad Abu Shaphe $^{3}$, Fuzail Ahmad ${ }^{4}$, Faizan Z Kashoo ${ }^{4}$, Amr S Shalaby ${ }^{5}$

${ }^{1}$ Department of Physiotherapy, KPC Medical College, Kolkata, India

${ }^{2}$ Department of Physiotherapy, Peerless Hospitex Hospital \& Research Center, Kolkata, India

${ }^{3}$ Department of Physical Therapy, College of Applied Medical Sciences, Jazan University, Jazan, Saudi Arabia

${ }^{4}$ Department of Physical Therapy and Health rehabilitation, Majmaah University, Majmaah, Saudi Arabia

${ }^{6}$ Faculty of Physical Therapy, Basic Science, Cairo University, Cairo, Egypt

\section{Corresponding Author:}

Mohammad Abu Shaphe ${ }^{3}$

Associate Professor

Department of Physical Therapy, College of Applied Medical Sciences, Jazan University, Jazan, Saudi Arabia

Email address: mshaphe@jazanu.edu.sa

\section{Abstract}

Background. Breast cancer related upper limb lymphedema (BCRL) is a common complication in post-mastectomy patients. It is known to cause upper limb disability, which subsequently may affect the grip strength and hand function. There is little evidence on the objective assessment of functional activities particularly hand function in women with BCRL. Therefore, this study objectively assesses the handgrip strength and hand functions in women with BCRL.

Method. A cross-sectional study design was conducted on a sample of women with $(\mathrm{n}=31)$ and without $(\mathrm{n}=31)$ BCRL. The Handgrip strength and hand functions were measured using a dynamometer and Jebsen-Taylor hand function test, respectively.

Results. The results showed a significantly reduced handgrip strength in women with BCRL as compared to age-matched healthy adult women for both right and left hands $(\mathrm{p}<0.05)$. Similarly, 
33 hand functions were significantly impaired in women with BCRL as compared to healthy adult

34 women $(\mathrm{p}<0.05)$. Reduction in handgrip strength and hand function in women with BCRL were

35 clinically meaningful as indicated by moderate to large effect sizes (Cohen's $d=0.61$ to 0.99 and

360.54 to 3.02 , respectively) in all outcomes except power handgrip strength in left hand (Cohen's d $37=0.38)$.

38 Conclusion. The results of this study indicate a significant reduction of hand grip strength and 39 hand function in women with BCRL. Our findings suggest that objective measures of grip strength 40 and function be included in the assessment of women with BCRL to better guide clinical decision 41 making and patient care, which may include management of impairment associated with hand 42 strength and function. Future studies that evaluate hand grip strength and function in a larger 43 sample which includes a more diverse age group of women with BCRL are warranted to confirm 44 the current findings.

\section{Introduction}

46 Breast cancer related upper limb lymphedema (BCRL) is common in patients who undergo 47 mastectomy. Lymphedema is a clinical condition in which accumulation of excess protein rich 48 tissue fluid and tissue alterations causes oedema (Karadibak \& Yavuzsen, 2015). The cancer registry program of twenty-five Population Based Cancer Registries (PBCRs) reports increasing trends for incidence and mortality of breast cancer in Indian women (Malvia et al., 2017). The cancer projection data showed that the number of breast cancer cases will increase to double by 2020 (Malvia et al., 2017). A previous study reported 42\% incidence of lymphedema in women who underwent mastectomy (Norman et al., 2009).

54 The major signs and symptoms lymphedema are: (a) increased limb circumference, (b) 55 restricted range of motion of affected joints, (c) stiffness, (d) sensory impairment in the hand, and 
56 (e) decrease use of affected limb for functional tasks (Gomes et al., 2014). Additionally,

57 chemotherapy may cause disruption in muscle metabolism (e.g., cytokine dysregulation, adenosine

58 triphosphate dysregulation, and deprivation of satellite cells) results muscle wasting leading to

59 reduced muscle strength and fitness level (Clarkson \& Kaufman, 2010).

60 Handgrip strength is essential for performing upper limb functional activities of daily living

61 (Rietman et al., 2003). Women with BCRL may have impaired upper limb use during functional

62 activities (Noelle, 2005; Carol, 2017). A cross-sectional study done in 2010, compared upper

63 extremity impairment and activity following breast cancer treatment between women with or

64 without BCRL and reported decreased grip strength and upper limb activities in women with

65 BCRL (Smoot et al., 2010). BCRL is also associated with restricted range of motion in the affected

66 limb, reduced functional ability, as well as physical disfigurement, pain, and skin problems. There

67 is a significant negative relationship present between severity of oedema and hand function

68 (Karadibak \& Yavuzsen, 2015).

69 In the previous study, while left and right handgrip strengths were reduced in women with

70 BCRL as compared to age-matched healthy women, no difference between left and right handgrip

71 strengths was found in women with BCRL (Gomes et al., 2014). Another study reported a

72 significantly impaired muscle strength and function in women with breast cancer who underwent

73 chemotherapy, or a radical mastectomy as compared to healthy women (Klassen et al., 2017).

74 More recently, Winters-Stone et al. (2019) reported a significantly lower handgrip strength and

75 function in older women with breast carcinoma than healthy older adults.

76 Most studies that evaluated the hand functional activities and strength in women with BCRL,

77 have used numerous types of questionnaires such as Hand Function Sort Questionnaire (HFS)

78 (Karadibak \& Yavuzsen, T, 2015) or Disability of Arm Shoulder Hand questionnaires (DASH) 
79 (Smoot et al., 2010), and Hand Dynamometer (Dawes et al., 2008), as their outcome measures.

80 While most studies have used subjective measures to evaluate hand function in women with

81 BCRL, few studies have used objective measure of hand function (Smoot et al., 2010; Wong et al.,

82 2019; Dollar et al., 2014; Kärki et al., 2005; Cantarero-Villanueva et al., 2012). For instance,

83 Smoot et al. (2010) used both subjective and objective measures such as DASH questionnaire and

84 a handheld dynamometer to evaluate hand function and strength, respectively in women with or

85 without BCRL. Cantarero-Villanueva et al. (2012) examined handgrip strength as an objective

86 measure of function in breast cancer survivors. It is important to objectively assess hand grip

87 strength and hand function so that appropriate and complete clinical assessment and intervention

88 can be implemented to address any impairments or functional limitations in women with BCRL

89 (Mak et al., 2015; Rietman et al., 2004; Hayes et al., 2010; Park et al., 2012).

90 There is limited research to determine objective assessment of hand function after surgery and

91 chemotherapy treatment in women with breast cancer. Therefore, the purpose of this study is to

92 (1) evaluate the hand grip strength and hand functional activities using objective outcome measures

93 in women with BCRL; and (2) to compare findings in women with BCRL to healthy control. In

94 women with BCRL, objective assessment of hand function will provide greater clarity and

95 precision regarding performance of functional activities of daily living than subjective assessment

96 alone, which will better guide clinical practice. The current study hypothesizes that grip strength

97 and objectively measured hand function will be impaired in women with BCRL compared to

98 women without BCRL.

99 Materials \& Methods

100 This study was an observational cross-sectional design with convenience sampling. All the 101 subjects were recruited from Ramaiah Medical College Hospital and HCG MSR Cancer Centre, 
102 Bengaluru, India. An ethical clearance was obtained from the Ethical Committee of Ramaiah

103 Medical College and Hospital (MEU-PT/EC/12/2018). Purpose of the study was explained to each

104 individual and a written informed consent was obtained.

105 The subjects were included based on the following criteria: (1) age between 35-65 years, (2)

106 had completed chemotherapy/surgery $\geq 6$ months, (3) women with BCRL for more than 3 months

107 old, (4) affecting the dominant hand and (5) self-reported pain score of seven or less on visual

108 analogue scale (because $\geq 7$ pain score might influence handgrip strength and function)

109 (Cantarero-Villanueva et al., 2012). Subjects were excluded if they were receiving radiotherapy,

110 who had a history of fracture or surgery in upper limb in last 3 months or had neuromuscular or

111 musculoskeletal disorders that would have prevented assessment of hand grip strength and

112 function. The control group included a convenience sample of 31 healthy age-matched women

113 without history of breast carcinoma.

\section{Objective Measures}

115 A hand dynamometer and pinch gauge/pinch meter were used to measure power grip and precision 116 grip strength and the Jebsen-Taylor hand function test (JTHFT) (Mak et al., 2015) tool kit was 117 used to assess hand function. Hand dynamometer and pinch gauge are valid instruments to assess 118 grip strength (Neumann et al., 2017; Lindstrom-Hazel et al., 2009; Shin et al., 2012). Handgrip 119 strength and function of both patient (i.e., women with BCRL) and healthy control (i.e., women 120 without BCRL) samples were evaluated in a similar fashion.

\section{Measurement of Power Grip Strength of Hand}

122 A baseline hand dynamometer was used to assess the power grip. Individuals were asked to hold 123 the hand dynamometer, where the elbow was in 90 degrees flexion and shoulder in neutral position. 
124 The individuals were asked to press the hand dynamometer as hard as they can, three times, and

125 the best value was taken from each hand (Smoot et al., 2010).

\section{Measurement of Precision Grip strength of Hand}

127 For assessing the precision grip, pinch gauge was used (Smoot et al., 2010). Individuals were asked 128 to hold the pinch gauge and press it in three different position, Tip of thumb to tip of index finger, 129 thumb pad to lateral aspect of index finger, and thumb pad to pad of index finger and pad of middle 130 finger (Tripod pinch). Individuals sat on a chair, their elbow was in 90 degrees flexion and shoulder 131 in neutral position. Instructions were given to the patients to press the pinch gauge in three different 132 position (Tip to tip, Key pinch, and Tripod pinch) as hard as they can. Each precision grip was 133 performed three times and the best value was taken from each hand.

\section{Assessment of Hand Function}

135 For assessing bilateral hand function, the Jebsen-Taylor hand function test (JTHFT) (Mak et al., 136 2015) tool was used. It is a valid and reliable tool which objectively measures the hand function 137 (Mak et al., 2015). It is a task specific tool, consisting of 7 tasks for assessing hand functions. The 138 tasks are: writing, picking up small common objects, and picking up large objects, card turning, 139 simulated feeding, and stacking checkers. Each task was measured by calculating time (Mak et al., 140 2015).

\section{Statistical analysis}

142 The data were tabulated in Microsoft Excel and the statistical program for social science software

143 for Window (version 17, SPSS Inc, Chicago, IL) was used for the statistical analyses. Descriptive 144 statistics was used to calculate the mean and standard deviation of the patient's age. A student t145 test was used to determine statistical difference of grip strength and hand function between 146 normative data and patient data. Additionally, the effect sizes were calculated using the Cohen's 
$147 \mathrm{~d}$ for each variable to evaluate clinically meaningful changes. Effect size were defined as: small (d

$148=<0.5)$, medium $(\mathrm{d}=0.50$ to 0.80$)$, and large $(\mathrm{d}=>0.80)($ Gärtner et al., 2010). Results were

149 considered statistically significant if $\mathrm{p}<0.05$. The sample size was calculated using estimation of 150 means from the formula $\left(\mathrm{n}=[\mathrm{Z} \alpha \sigma / \mathrm{d}]^{2}\right)$. Where $\mathrm{Z} \alpha$ is $95 \%$ confidence level, $\sigma$ is standard deviation, 151 and $\mathrm{d}$ is the margin of error. The Z $\alpha$ was 1.96, the Standard deviation was 2.1 of writing in JTHFT 152 and the margin of error was 0.75 (Voogd et al., 2003). The estimated sample size came to 31.

\section{Results}

154 A total of 31 women with BCRL and 31 age-matched healthy women were included in the study 155 (Table 1). Out of 31 subjects, 21 subjects had right hand lymphedema and 10 subjects had left 156 hand lymphedema. Sixty-eight percent women with BCRL and 58\% healthy women were right 157 hand dominant. Mean age of the patients and healthy control groups were $55.5( \pm 8.4)$ and $55.7( \pm$ 158 8.1) years, respectively.

159 Table 2 presents the result of power grip and precision grip strength of right and left hands.

160 Compared to healthy controls, there were significant reductions of both power and precision grip 161 strengths $\mathrm{p}<0.05$. Reductions in handgrip strength in women with BCRL were clinically 162 meaningful as indicated by moderate to large effect sizes (Cohen's $d=0.61$ to 0.99 ) in all handgrip 163 strength except power handgrip strength in left hand (Cohen's $d=0.38$ ).

164 Table 3 compares the activities of hand functions in women with and without BCRL. The hand 165 functions were significantly reduced across all activities in women with BCRL when compared to 166 the healthy controls $(\mathrm{p}<0.05)$. Reduction in hand function in women with BCRL were clinically 167 meaningful as indicated by moderate to large effect sizes (Cohen's $d=0.54$ to 3.02, respectively) 168 in all variables of hand functions. 


\section{Discussion}

170 The present study examined the hand grip strength and hand functional activities in women with

171 BCRL. Findings of the study indicate significant reduction in the power grip and precision grip

172 strengths in women with BCRL as compared to age-matched healthy adult women. The results of

173 the hand function also showed significantly increased time to complete the task performance.

174 Reduction in handgrip strength and hand function in women with BCRL were also clinically

175 meaningful as determined by moderate to large effect sizes (Cohen's $d=0.61$ to 0.99 and 0.54 to

176 3.02, respectively) in all outcomes except power handgrip strength in left hand (Cohen's d=0.38).

177 Reduced strength has been known to have debilitating effects on women with BCRL. Most 178 studies demonstrate that upper limb lymphedema negatively affects the hand grip strength (Wong 179 et al., 2019). The same was found to be true among women with BCRL in the current study, mean 180 of the dominant right-hand power grip was $23.8 \mathrm{~kg}$ and dominant left hand was $22.2 \mathrm{~kg}$ when 181 compared to the control group of 29.4 and 25.5, respectively. The reduction of grip strength could 182 be due to swelling in hand and wrist which in turn leads to decreased wrist and finger range of 183 motion (ROM) and reduction of initiation of wrist extension and finger flexion (Smoot et al., 2010).

184 The position of producing a power grip for normal individual is, wrist in slight extension and elbow 185 in 90 degrees of flexion, in BCRL patients the wrist extension is reduced due to swelling resulting in active insufficiency of hand muscles, which could reduce the strength of grip. A study conducted by Dawes et al. (2008) found similar results where women with BCRL had lesser hand grip strength, and shoulder ROM and other hand morbidities, which led to impairment. In precision grip strength, the activity of tip, key and tripod pinch requires much finer motor control and is 
192 during gripping activities (Karadibak \& Yavuzsen, 2015; Smoot et al., 2010), this could be the 193 probable reason for the reduced precision grip strength in the studied subjects.

194 BCRL and its complications involving impaired upper limb function are well established 195 sequelae among breast cancer survivors. About $13-28 \%$ of breast cancer survivors post treatment 196 when surveyed have reported limitations in daily activities (Voogd et al., 2003). The present 197 participants when objectively assessed (JTHFT) for their hand function showed similar results to 198 that available in literature. For the JTHFT when administered to the women with BCRL, the 199 duration of each activity like writing, picking up small common objects, and picking up large 200 objects, card turning, simulated feeding, and stacking checkers performance was increased. The 201 overall time taken for completion of tasks was 68.8 seconds for right hand dominant and 100.3 202 seconds for left hand dominant.

203 While performing JTHFT, the tasks require power grip and precision grip equally, like picking 204 up large and heavy objects, handwriting, simulated feeding etc. Reduced power grip strength and 205 precision grip strength will have implications on activity performance. Our subjects also showed 206 reduced strength and task time was increased, thereby we can assume that strength does play a role 207 in performing of hand functions. A study conducted by Dawes et al. (2008) reported that when 208 DASH questionnaire along with grip strength assessment of women with BCRL was analyzed, the 209 scores were higher in women who had self-reported symptoms of lymphedema, indicating activity 210 limitation and participatory restriction. This reduction of hand function could be because of the 211 reduction in power grip strength and precision grip strength and reduction of kinesthetic sense 212 (Karadibak \& Yavuzsen, 2015), thus suggesting that impairment in hand grip strength plays a part 213 in performing hand function. Loss of muscle strength and lack of movement in articulation could 
214 also add to the reasons for impaired hand function (Karadibak \& Yavuzsen, 2015; Rietman et al., 215 2003; Smoot et al., 2010; Dawes et al., 2008; Kärki, 2005).

216 BCRL or hand oedema significantly affects functional mobility and activities of daily livings 217 of upper extremity (Karadibak \& Yavuzsen, 2015; Rietman et al., 2003; Smoot et al., 2010; Dawes 218 et al., 2008). Additionally, women with BCRL may develop weaknesses and restriction of shoulder 219 muscles and range of motion and reduced quality of life (Karadibak \& Yavuzsen, 2015). Voogd et 220 al. (2003) reported reduced daily functional skills, lack of energy and motivation, and reduced 221 quality of life.

\section{Limitations and directions for future research}

223 The current study acknowledged some limitations. First, this study used a cross-sectional design, 224 therefore, a causal relationship between BCRL, and hand grip strength and function could not be 225 established. Future prospective longitudinal studies that evaluate hand function during and after 226 rehabilitation of women with BCRL are warranted to examine changes in hand grip strength and 227 function as compare to age matched healthy individuals. Second, the results of this study were limited to the specific age groups (i.e., 35 to 65 years), hence generalization of this results in younger (e.g., < 35 years) or older (e.g., > 65 years) women with BCRL need caution. Further studies that included a more diverse age group (e.g., young to elderly) are required to examine influence of age on hand grip strength and function in women with BCRL. Third, although the current study estimated a priori sample size, larger sample might give better results.

\section{Conclusions}

234 The results of this study indicate a significant reduction of hand grip strength and hand function in 235 women with BCRL. Our findings suggest that objective measures of grip strength and function be 236 included in the assessment of women with BCRL to better guide clinical decision making and 
237 patient care, which may include management of impairment associated with hand strength and

238 function. Future studies that evaluate hand grip strength and function in a larger sample with a 239 more diverse age group of women with BCRL population are warranted to confirm the current 240 findings.

\section{Competing interest}

242 "The authors declare that they have no competing interests".

243

244 References

245 Cantarero-Villanueva, I., Fernández-Lao, C., Díaz-Rodríguez, L., Fernández-de-Las-Peñas, C., 246 Ruiz, J. R., \& Arroyo-Morales, M. 2012. The handgrip strength test as a measure of function 782. https://doi.org/10.1097/PHM.0b013e31825f1538

Carol, A. Oatis. 2017. Kinesiology: The Mechanics and Pathomechanics of Human Movement. Third Edition. Wolters Kluwer. 1061-1062.

Clarkson, P. M., \& Kaufman, S. A. 2010. Should resistance exercise be recommended during breast cancer treatment? Medical hypotheses, 75(2), 192-195.

Dawes, D. J., Meterissian, S., Goldberg, M., \& Mayo, N. E. 2008. Impact of lymphoedema on arm function and health-related quality of life in women following breast cancer surgery. Journal of rehabilitation medicine, 40(8), 651-658. https://doi.org/10.2340/16501977-0232

Dollar, A.M. 2014. Classifying Human Hand Use and the Activities of Daily Living. In: 
Development. Springer Tracts in Advanced Robotics, vol 95. Springer, Cham. https://doi.org/10.1007/978-3-319-03017-3_10

262 263

264 265 266

Gärtner, R., Jensen, M. B., Kronborg, L., Ewertz, M., Kehlet, H., \& Kroman, N. 2010. Selfreported arm-lymphedema and functional impairment after breast cancer treatment--a nationwide study of prevalence and associated factors. Breast (Edinburgh, Scotland), 19(6), 506-515. https://doi.org/10.1016/j.breast.2010.05.015

Gomes, P.R.L., Freitas Junior, I.F., da Silva, C.B., Gomes, I.C., Rocha, A.P.R., Salgado, A.S.I., \& Carmo, E.M.D. 2014. Short-term changes in handgrip strength, body composition, and lymphedema induced by breast cancer surgery. Revista Brasileira de Ginecologia e Obstetrícia, 36(6), 244-250. https://doi.org/10.1590/S0100-720320140005004

Goulet-Pelletier, J.-C., \& Cousineau, D. 2018. A review of effect sizes and their confidence intervals, Part $\{\mathrm{I}\}$ : The Cohen's d family. Tutorials in Quantitative Methods for Psychology, 14(4), 242-265. https://doi-org.sdl.idm.oclc.org/10.20982/tqmp.14.4.p242

Hayes, S. C., Rye, S., Battistutta, D., DiSipio, T., \& Newman, B. 2010. Upper-body morbidity following breast cancer treatment is common, may persist longer-term and adversely influences quality of life. Health and quality of life outcomes, 8, 92. https://doi.org/10.1186/1477-7525-8-92

Karadibak, D., \& Yavuzsen, T. 2015. Evaluation of kinesthetic sense and hand function in women with breast cancer-related lymphedema. Journal of physical therapy science, 27(6), 16711675. https://doi.org/10.1589/jpts.27.1671

Kärki, A., Simonen, R., Mälkiä, E., \& Selfe, J. 2005. Impairments, activity limitations and participation restrictions 6 and 12 months after breast cancer operation. Journal of rehabilitation medicine, 37(3), 180-188. https://doi.org/10.1080/16501970410024181 
283 Klassen, O., Schmidt, M. E., Ulrich, C. M., Schneeweiss, A., Potthoff, K., Steindorf, K., \&

284 Wiskemann, J. 2017. Muscle strength in breast cancer patients receiving different treatment 285 regimes. Journal of cachexia, sarcopenia and muscle, 8(2), 305-316. 286 https://doi.org/10.1002/jcsm.12165

287 Lindstrom-Hazel, D., Kratt, A., \& Bix, L. 2009. Interrater reliability of students using hand and 288 289 pinch dynamometers. The American journal of occupational therapy: official publication of the American Occupational Therapy Association, 63(2), 193-197. https://doi.org/10.5014/ajot.63.2.193

291

292

293

294

295

296

297

298

299

300

301

302

303

304

305

Mak, M. K., Lau, E. T., Tam, V. W., Woo, C. W., \& Yuen, S. K. 2015. Use of Jebsen Taylor Hand Function Test in evaluating the hand dexterity in people with Parkinson's disease. Journal of hand therapy : official journal of the American Society of Hand Therapists, 28(4), 389-395. https://doi.org/10.1016/j.jht.2015.05.002

Malvia, S., Bagadi, S. A., Dubey, U. S., \& Saxena, S. 2017. Epidemiology of breast cancer in Indian women. Asia-Pacific journal of clinical oncology, 13(4), 289-295. https://doi.org/10.1111/ajco.12661

Neumann, S., Kwisda, S., Krettek, C., \& Gaulke, R. 2017. Comparison of the Grip Strength Using the Martin-Vigorimeter and the JAMAR-Dynamometer: Establishment of Normal Values. In vivo (Athens, Greece), 31(5), 917-924. https://doi.org/10.21873/invivo.11147

Noelle, M.A. 2005. The Wrist and Hand Complex. Joint Structure \& Function, A Comprehensive Analysis. Fourth Edition. F A Davis Philadelphia. 340-346.

Norman, S. A., Localio, A. R., Potashnik, S. L., Simoes Torpey, H. A., Kallan, M. J., Weber, A. L., Miller, L. T., Demichele, A., \& Solin, L. J. 2009. Lymphedema in breast cancer survivors: incidence, degree, time course, treatment, and symptoms. Journal of clinical oncology: 
306

307

308

309

310

311

312

313

314

315

316

317

318

319

320

321

322

323

324

325

326

327

official journal of the American Society of Clinical Oncology, 27(3), 390-397. https://doi.org/10.1200/JCO.2008.17.9291

Park, J. E., Jang, H. J., \& Seo, K. S. 2012. Quality of life, upper extremity function and the effect of lymphedema treatment in breast cancer related lymphedema patients. Annals of rehabilitation medicine, 36(2), 240-247. https://doi.org/10.5535/arm.2012.36.2.240

Rietman, J. S., Dijkstra, P. U., Hoekstra, H. J., Eisma, W. H., Szabo, B. G., Groothoff, J. W., \& Geertzen, J. H. 2003. Late morbidity after treatment of breast cancer in relation to daily activities and quality of life: a systematic review. European journal of surgical oncology: the journal of the European Society of Surgical Oncology and the British Association of Surgical Oncology, 29(3), 229-238. https://doi.org/10.1053/ejso.2002.1403.

Rietman, J. S., Dijkstra, P. U., Debreczeni, R., Geertzen, J. H., Robinson, D. P., \& De Vries, J. 2004. Impairments, disabilities, and health related quality of life after treatment for breast cancer: a follow-up study 2.7 years after surgery. Disability and rehabilitation, 26(2), 78-84. https://doi.org/10.1080/09638280310001629642

Shin, H., Moon, S. W., Kim, G. S., Park, J. D., Kim, J. H., Jung, M. J., Yoon, C. H., Lee, E. S., \& Oh, M. K. 2012. Reliability of the pinch strength with digitalized pinch dynamometer. Annals of rehabilitation medicine, 364-399. https://doi.org/10.5535/arm.2012.36.3.394

Smoot, B., Wong, J., Cooper, B., Wanek, L., Topp, K., Byl, N., \& Dodd, M. 2010. Upper extremity impairments in women with or without lymphedema following breast cancer treatment. Journal of cancer survivorship: research and practice, 4(2), 167-178. https://doi.org/10.1007/s11764-010-0118-x 
328 Voogd, A. C., Ververs, J. M., Vingerhoets, A. J., Roumen, R. M., Coebergh, J. W., \& Crommelin, 329 M. A. 2003. Lymphoedema and reduced shoulder function as indicators of quality of life 330 after axillary lymph node dissection for invasive breast cancer. The British journal of 331 surgery, 90(1), 76-81. https://doi.org/10.1002/bjs.4010

332 Winters-Stone, K. M., Medysky, M. E., \& Savin, M. A. 2019. Patient-reported and objectively 333 measured physical function in older breast cancer survivors and cancer-free controls. Journal 334 of geriatric oncology, 10(2), 311-316. https://doi.org/10.1016/j.jgo.2018.10.006

335 Wong, M. L., Cooper, B. A., Paul, S. M., Abrams, G., Topp, K., Kober, K. M., Chesney, M. A., 336 Mazor, M., Schumacher, M. A., Conley, Y. P., Levine, J. D., \& Miaskowski, C. 2019. Age337 related differences in patient-reported and objective measures of chemotherapy-induced 338 peripheral neuropathy among cancer survivors. Supportive care in cancer: official journal of 339 the Multinational Association of Supportive Care in Cancer, 27(10), 3905-3912. $340 \quad$ https://doi.org/10.1007/s00520-019-04695-3 
Table $\mathbf{1}$ (on next page)

Participants characteristics. 
1 Table 1 Participants characteristics.

\begin{tabular}{cccc}
\hline Variables & $\begin{array}{c}\text { Women with } \\
\text { BCRL } \\
\text { Mean } \pm \text { SD }\end{array}$ & $\begin{array}{c}\text { Women without } \\
\text { BCRL } \\
\text { Mean } \pm \text { SD }\end{array}$ & P (t) \\
\hline Age (years) & $55.5 \pm 8.4$ & $55.7 \pm 8.1$ & $0.890(0.138)$ \\
Body mass index $\left(\mathrm{kg} / \mathrm{m}^{2}\right)$ & $24.5 \pm 0.7$ & $24.4 \pm 0.8$ & $0.842(0.201)$ \\
Hand dominance (\% of right) & $68 \%$ & $58 \%$ & $0.439(0.779)$ \\
Side of BCRL (right/left) & $21 / 10$ & & \\
Duration of BCRL (months) & $8.7 \pm 3.4$ & & \\
Treatment of cancer & 11 & & \\
Surgery & 11 & & \\
Surgery and chemotherapy & 9 & & \\
Surgery and radiotherapy & $10.4 \pm 2.1$ & & \\
Number of nodes removed & & & \\
BCRL: Breast Cancer related Lymphedema & & \\
\hline
\end{tabular}


Table 2 (on next page)

Comparison of grip strength between women with and without breast cancer related lymphedema 
1 Table 2 Comparison of grip strength between subjects with and without BCRL

\begin{tabular}{|c|c|c|c|c|c|c|c|c|}
\hline \multirow[b]{2}{*}{ Variables } & \multicolumn{3}{|c|}{ RIGHT } & \multicolumn{5}{|c|}{ LEFT } \\
\hline & $\begin{array}{l}\text { Women with } \\
\text { BCRL } \\
\text { Grip strength } \\
\text { (Kg.) } \\
\text { Mean } \pm \text { SD }\end{array}$ & $\begin{array}{l}\text { Women without } \\
\text { BCRL } \\
\text { Grip strength } \\
\text { (Kg.) } \\
\text { Mean } \pm \text { SD }\end{array}$ & $\begin{array}{l}\mathrm{p} \text { value } \\
(<0.05)\end{array}$ & $\begin{array}{l}\text { Effect size } \\
\text { (Cohen's } \\
\text { d) }\end{array}$ & $\begin{array}{l}\text { Women } \\
\text { with BCRL } \\
\text { Strength } \\
\text { Mean } \pm \text { SD }\end{array}$ & $\begin{array}{l}\text { Women without } \\
\text { BCRL } \\
\text { Grip strength } \\
\text { (Kg.) } \\
\text { Mean } \pm \text { SD }\end{array}$ & $\begin{array}{l}\mathrm{p} \text { Value } \\
(<0.05)\end{array}$ & $\begin{array}{l}\text { Effect size } \\
\text { (Cohen's } \\
\text { d) }\end{array}$ \\
\hline Power grip & $23.8 \pm 9.9$ & $29.4 \pm 8.3$ & 0.019 & 0.61 & $22.2 \pm 9.3$ & $25.5 \pm 7.9$ & 0.013 & 0.38 \\
\hline $\begin{array}{l}\text { Precision grip } \\
\text { Tip pinch }\end{array}$ & $4.1 \pm 1.1$ & $5.2 \pm 1.7$ & 0.004 & 0.76 & $3.9 \pm 1.1$ & $5.0 \pm 1.7$ & 0.004 & 0.77 \\
\hline Key pinch & $6.1 \pm 1.3$ & $7.5 \pm 2.6$ & 0.013 & 0.68 & $5.9 \pm 1.3$ & $7.3 \pm 2.9$ & 0.033 & 0.62 \\
\hline Tripod pinch & $5.4 \pm 1.1$ & $7.5 \pm 2.8$ & 0.001 & 0.98 & $5.2 \pm 1.1$ & $7.3 \pm 2.8$ & 0.001 & 0.99 \\
\hline
\end{tabular}


Table 3(on next page)

Comparison of hand functions between women with and without breast cancer related lymphedema 
Table 3 Comparison of hand functions between subjects with and without BCRL

\begin{tabular}{|c|c|c|c|c|c|c|c|c|}
\hline \multirow[b]{2}{*}{ Variables } & \multicolumn{4}{|c|}{ RIGHT } & \multicolumn{4}{|c|}{ LEFT } \\
\hline & $\begin{array}{l}\text { Women with } \\
\text { BCRL } \\
\text { Hand function } \\
\text { (Sec) } \\
\text { Mean } \pm \text { SD }\end{array}$ & $\begin{array}{c}\text { Women } \\
\text { without BCRL } \\
\text { Hand } \\
\text { function } \\
\text { (Sec) } \\
\text { Mean } \pm \text { SD }\end{array}$ & $\begin{array}{c}\mathrm{p} \\
\text { valu } \\
\mathrm{e} \\
(<0 . \\
05)\end{array}$ & $\begin{array}{c}\text { Effect } \\
\text { size } \\
\text { (Cohen's } \\
\text { d) }\end{array}$ & $\begin{array}{l}\text { Women } \\
\text { with } \\
\text { BCRL } \\
\text { Hand } \\
\text { function } \\
\text { (Sec) } \\
\text { Mean } \pm \\
\text { SD }\end{array}$ & $\begin{array}{l}\text { Women } \\
\text { without } \\
\text { BCRL } \\
\text { Hand } \\
\text { function } \\
(\mathrm{Sec}) \\
\text { Mean } \pm \text { SD }\end{array}$ & $\begin{array}{l}\mathrm{p} \\
\text { value } \\
(<0.05 \\
)\end{array}$ & $\begin{array}{l}\text { Effect } \\
\text { size } \\
\text { (Cohe } \\
\text { n's d) }\end{array}$ \\
\hline Card turning & $7.5 \pm 2.5$ & $4.3 \pm 1.6$ & 0.010 & 1.53 & $8.2 \pm 2.7$ & $4.9 \pm 1.4$ & 0.001 & 1.53 \\
\hline Picking up small objects & $7.1 \pm 1.7$ & $4.9 \pm 1.1$ & 0.002 & 1.54 & $7.4 \pm 2.1$ & $5.2 \pm 1.5$ & 0.021 & 1.21 \\
\hline Simulated feeding & $8.4 \pm 1.4$ & $5.1 \pm 0.8$ & 0.003 & 2.89 & $9.7 \pm 1.4$ & $5.9 \pm 1.1$ & 0.003 & 3.02 \\
\hline Stacking checkers & $3.8 \pm 0.9$ & $3.3 \pm 0.6$ & 0.035 & 0.65 & $4.1 \pm 1.4$ & $3.5 \pm 0.7$ & 0.001 & 0.54 \\
\hline Picking up large objects & $4.3 \pm 1.0$ & $2.9 \pm 0.6$ & 0.001 & 1.70 & $5.3 \pm 2.5$ & $3.1 \pm 1.4$ & 0.001 & 1.09 \\
\hline Picking up heavy objects & $4.3 \pm 0.9$ & $2.9 \pm 0.6$ & 0.023 & 1.83 & $5.2 \pm 1.9$ & $3.2 \pm 1.1$ & 0.001 & 1.29 \\
\hline Handwriting & $33.2 \pm 26.4$ & $21.2 \pm 12.2$ & 0.025 & 0.58 & $\begin{array}{c}64.5 \pm \\
32.1\end{array}$ & $39.8 \pm 10.1$ & 0.001 & 1.04 \\
\hline
\end{tabular}

